\title{
Gen Transfer Teknolojisi ve Yağ asidi Kompozisyonlarına Katkısı- CRSPR/Cas Teknolojisi
}

\author{
Barıș Eren $^{1 *}$ \\ 1* Iğdır Üniversitesi, Ziraat Fakültesi, Tarımsal Biyoteknoloji Bölümü, Iğdır, Türkiye, (ORCID: 0000-0002-3852-6476), bariseren@ gmail.com
}

(İlk Geliş Tarihi Aralık 2020 ve Kabul Tarihi Ocak 2021 )

(DOI: 10.31590/ejosat.853850)

ATIF/REFERENCE: Eren, B. (2021). Gen Transfer Teknolojisi ve Yağ asidi Kompozisyonlarına Katkısı- CRSPR/Cas Teknolojisi. Avrupa Bilim ve Teknoloji Dergisi, (22), 300-305.

$\ddot{O} \mathbf{z}$

Son yüzyılda biyoteknolojik çalışmalarla canlı organizmaların anlaşılmasına ve organizmalar arasında genetik bilgi aktarımına olanak sağlamıştır. Genetik mühendisliği sahasının genişlemesi tarımsal faaliyetlerde verim, kalite, hastalık ve zararlılara dirençli, biyotik/abiyotik stres faktörlerine dayanıklı çeşitlerin geliştirilmesine olanak sağlamıştır. Gen transfer teknolojisinin bir diğer çalışma sahası ise bitki besin içeriklerinde değişimi mümkün kılan çalışmalar olmuştur. Genetik modifikasyonlarla besin kalitesi, kimyasal içeriğin arttırılması/azaltılması, beslenme fizyolojisine uygunluk gibi önemli ekonomik katkılar sağlamıştır. Gen modifikasyon çalışmalarıyla bitki besin bileşenlerinin arttırılması yada azaltılmasıyla uygun fizyolojik beslenme amaçlanmıştır. Son yapılan çalışmalarla kolza, haşhaş, patates, soya, ayçiçeği gibi bitkilerde ekonomik değeri yüksek besin içerikleri elde edilmiştir. Bitki besin içeriği değişiminde yeni bir teknik olan CRISPR/cas teknolojisi ile kolza, ayçiçeği, zeytin, ketencik gibi çeşitli bitkilerde MUFA/PUFA içeren yağlar elde edilmiştir. Ayrıca yapılan son çalışmalar ile CRISPR/Cas ile düzenlenmiş bitkilerin GDO'lu bitkiler katagorisine tabi tutulmadığı gösterilmiştir. Ancak gen modifikasyonu ile elde edilen tüm ürünlerin olası risklerinin azaltılması için insan-çevre ilişkilerinin gerekli testlere tabi tulması gerekmektedir.

Anahtar Kelimeler: Biyoteknoloji, Gen transferi, Yağ asidi, CRSPR/Cas.

\section{Gene Transfer Technology and Its Contribution to Oil Acid Compositions- CRSPR / Cas Technology}

\begin{abstract}
In the last century, biotechnological studies have enabled the understanding of living organisms and the transfer of genetic information between organisms. The expansion of the field of genetic engineering has enabled the development of yield, quality, disease and pest resistant varieties that are resistant to biotic / abiotic stress factors in agricultural activities. Another field of study of gene transfer technology has been studies that enable changes in plant nutrient contents. With genetic modifications, it has made important economic contributions such as food quality, increase / decrease of chemical content, compliance with nutritional physiology. Proper physiological nutrition is aimed by increasing or decreasing plant nutritional components with gene modification studies. With the latest studies, nutrients with high economic value have been obtained in plants such as rapeseed, poppy, potato, soybean and sunflower. With the CRISPR / cas technology, which is a new technique in plant nutrient content change, oils containing MUFA / PUFA have been obtained in various plants such as rapeseed, sunflower, olive, camelina. In addition, with the recent studies, it has been shown that the plants arranged with CRISPR / Cas are not subjected to the GMO plants category. However, humanenvironment relationships should be subjected to necessary tests in order to reduce the possible risks of all products obtained by gene modification.
\end{abstract}

Keywords: Biotechnology, Gene transfer, Oil acid, CRSPR/Cas.

* Sorumlu Yazar: bariseren@gmail.com 


\section{Giriş}

Biyoteknoloji, genetik materyale sahip tüm canlılarda oluşan ya da oluşabilecek sorunların çözümü ve istenilen faydalı özelliklere sahip ürünlerin elde edilmesi için biyolojik karakterlere dayalı popüler bir bilim dalı olarak bilinmektedir. Biyoteknolojik çalışmalar biyolojik mekanizmaların tam olarak anlaşılmadığı yüz yıllar öncesine kadar dayanmaktadır (Demirel, 2020). İnsanlar için peynir, ekmek, sirke, bira ve hayvan beslemesinde ise bitkilerin klasik 1slah metotlarıla geliştirilmesinde biyoteknolojik yöntemler kullanılmıştır. Ayrıca mikroorganizmalar aracılığıyla farklı ürünlerin ortaya konmasında biyoteknolojiden faydalanılmıştır. Son yarım yüzyılda gen transferi, hücre doku kültürü ve rekombinant DNA teknolojisi gibi gelişmelerle birlikte biyoteknolojinin çalışma sahası daha da genişlemiştir.

Biyoteknolojinin, tıp, bitki ıslahı, kozmetik ilaç sanayi, kimyasal maddelerin üretimi, atık zararlarının giderilmesi, rekombinant DNA teknolojisi, klonlama ve biyolojik silah üretimi gibi birçok çalışma sahası olduğu bilinmektedir (Awais et al., 2010). Biyoteknolojinin en geniş çalışma sahalarından biri hiç şüphesiz tarımdır. Tarımsal faaliyetlerde ürün yetiştirilmesi ve geliştirilmesi konusunda genetik modifikasyonlarla geleneksel tarım faaliyetlerinin de ötesine geçilmiştir. Son yarım asırda biyoteknolojik gelişmeler ile istenilen özelliklerin elde edilmesi amaciyla bir organizmadan diğerine gen transferi mümkün hale gelmiştir (Uzogara, 2000; Mucci and Hough, 2003). Hücre ve doku kültürü teknikleri, in vitro olarak izole edilmiş bitki hücrelerinden veya dokudan, yani meristemler, olgunlaşmamış embriyolar, anterler, mikrosporlar, protoplastlar gibi bitkileri yeniden üretmeyi hedefler. Moleküler yöntemler, genlerin belirlenmesi, izolasyonu ve transferi için teknikleri içerir. Manipüle edilmiş hücrelerin ve dokuların tüm bitkilere yeniden oluşturulması gerektiğinden, verimli hücre ve doku kültürü yöntemleri genetik mühendisliğinin ayrılmaz bir parçasıdır. $\mathrm{Bu}$ şekilde üretilen yeni genotipler, yeni çeşitlere doğru sadece ilk adımdır; bunlar daha ileri uygulamalı ıslah programları için temel germplazmadır (Thierfelder ve ark., 1992). Bu çalışmalarla, genetik materyalin anlaşılması ve transferiyle birlikte tarımsal ürünlerin geliştirilme süreci de hız kazanmıştır. Tarımsal alanda hastalık ve zararlılara dayanıklı genotiplerin geliştirilmesi, bitki verim ve kalite özelliklerinin arttırılması bu çalışmaların en güzel örnekleridir.

Artan dünya nüfusu ile birlikte beslenme gereksinimini karşılayacak yeterli ve besin değeri yüksek gıdaya ihtiyaç artacaktır. Geleneksel tarımın aksine seleksiyon ve melezleme yöntemleriyle verim ve kalitenin, hastalık, zararlılar ve stres faktörlerine dayanıklılığın arttırılması biyoteknolojinin hedeflerini oluşturmaktadır. Böylelikle yararlı türlerin ortaya çıkarılması, bitki verim, kalite ve sürdürülebilirliği ile genetik modifikasyonlara yer verilmektedir (Ohlrogge, 1994). Bunlarla birlikte biyoteknolojik çalışmalar, bitki besin içeriklerinin değiştirilmesine de olanak sağlamaktadır. Bunun sonucu olarak biyoteknolojik araçlar besin kalite ve ihtiyacın giderilmesine katkısı oldukça büyük olacaktır. Özellikle beslenme fizyolojisine katkı sağlaması amacıyla bitki besin içeriklerinde kimyasal değişimle yararlı formlara dönüştürülerek zenginleştirilebilmektedir.

\section{Biyoteknolojik Kimyasal İçeriğin Değişimi \\ Bitkilerde}

Canlıların biyolojik mekanizmalarının anlaşılması ve son yarım yüzyılda artan biyoteknolojik çalışmalarla gen aktarımı canlı organizmalar arasında mümkün hale gelmiştir. Canlı genomunun kazanımı ve gen modifikasyonu yöntemlerinin gelişmesi istenen özelliklerin kontrolünü sağlayan genlerin eklenip çıkarılmasına imkan sağlamıştır (Lack, 2002). Bunun sonucu olarak birçok bitkide istenen özelliklerin elde edilmesi için genetik modifikasyonun yapıldığı söylenebilir (Uzogara, 2000). Ayrıca biyoteknolojik çalışmalarla bazı besin içeriklerinin modifikasyonu ile direnç kazandırılmaktadır. $\mathrm{Bu}$ modifikasyonlar ile elde edilen besinler ve besin içerikleri endüstriyel olarak kullanılmaktadır. Besin içeriklerinde yapılan modifikasyonlardaki amaç, fizyolojik açıdan daha uygun hale getirmek, bitki besin içeriği az olan bileşenlerin miktarının arttırılması ya da azaltılması ve istenmeyen özelliklerin baskılanması olarak söylenebilir. Örneğin gen modifikasyonu ile patatesten elde edilen Cyclodextrin gida ve eczacılık alanlarında aromatik bileşiklerin stabilizasyonunda kullanılmaktadır. Ayrıca aynı bileşik istenmeyen (kolesterin ve acılık) özelliklerinde baskılanmasında kullanılmaktadır. Yine beta-karoten biyosentez geniyle modifiye edilmiş olan altın pirinç içerdiği A vitamini miktarında ve demir birikimi için önemli bir genetik mühendisliği ürünü olduğu ortaya konmuştur.

Biyoteknolojik uygulamalar ile birlikte birçok tarımsal ürün içerdikleri alkaloit, yağ ve proteinler sayesinde endüstriyel olarak değer kazanmaktadır. Bitkilerin yağ asidini sentezleme mekanizmaları karmaşık bir olay olmakla beraber çok farklı enzimler bu sentezleme olayında yer alabilmektedir (Ohlrogge, 1994). Biyoteknolojik yaklaşımlar ile yăg asidi sentezinde rol alan enzimlerin kompozisyonunun değiştirilebilmesi mümkün hale gelmiştir. Örneğin; kolza yağının yă̆ asidi kompozisyonu Stearoyl-acyl taşıyıcı desaturaz enzimini kodlayan genin antisens ifadesi ile değiştirilmiştir (Turgut vd., 2001). Genetik modifikasyonla birlikte geliştirilen ürünler tıp, gıda, kozmetik, kimya ve boya endüstrilerinde kullanılmaktadır. Böylelikle yararlı forma dönüştürülen besin içeriklerine sahip ürünlerin ticari değeri artmaktadır. Örneğin kolza bitkisinde yapılan son çalışmalar ile yağ asidi bileşenlerinde $\mathrm{C} 10$ ve $\mathrm{C} 22$ atomları içeren çeşitlerin geliştirildiği, yine kolza bitkisi içerdiği yă̆ asidi kompozisyonlarının değiştirilmesi ile beslenme fizyolojisine katkı sağladığı belirlenmiştir (Wenzel ve Mohler, 2001; Turgut ve ark., 2001). Ayrıca haşhaş bitkisi içerdiği yağ asidi bileşenlerinin geliştirilmesiyle kolesterol dengesini sağlamada ve bazı hastalıkların önlenmesine katkı sağladığı bildirilmiştir (Peter, 2001; Ghafoor et al., 2019).

\subsection{CRSPR/Cas Teknolojisi ve Yă̆ Asidi Kompozisyonlarına Katkısı}

Genetik mühendisliği teknikleri biyotik/abiyotik stres toleransı ve yă̆ kompozisyonunun değiştirilmesi/arttırılması gibi önemli özelliklerin iyileştirilmesine olanak sağladığından çok sayıda yă̆ bitkisinde uygulanmıştır. Geleneksel ıslahın aksine rekombinant DNA teknolojisi herhangi bir organizmadan arzu edilen genlerin yağ bitkilerine aktarılmasına izin vermektedir. Böylece yağ bitkilerinde 1slah ile üstün özelliklere sahip yeni genotiplerin geliştirilmesi mümkün olmaktadır. Ancak, genetik mühendisliği ile oluşturulmuş GDO'lu bitkilerin gelişimi büyük ölçüde düzenleyici sistem süreçlerinden etkilenmektedir. $\mathrm{Bu}$ düzenlemeler aynı zamanda GDO'lu 
bitkilerin biyogüvenliğine tüketicilerin inanmasına yardım etmektedir (Stirling et al., 2015).

Tablo 1. Bazı bitkilerde kimyasal içeriğin modifiye edildiği genetik kaynaklar.

\begin{tabular}{|c|c|c|}
\hline Bitki & Kimyasal İçerik & Genetik Kaynak \\
\hline $\begin{array}{l}\text { Soya Fasulyesi, } \\
\text { Kolza, Ayçiçeği }\end{array}$ & $\begin{array}{l}\text { Yağ asidi içeriğinin } \\
\text { değiştirilmesi, doymamış yăg } \\
\text { asitlerinin arttırılması }\end{array}$ & FAD3 VE FAD2 geninin klonlanmas1 \\
\hline Tütün, Yonca & $\begin{array}{l}\alpha \text {-amilaz, Fitaz, Xylanaz gibi } \\
\text { enzimlerin ifadesi }\end{array}$ & $\begin{array}{l}\text { B. lichniformis ( } \alpha \text {-amilaz), A. niger (Fitaz), C. thermocellum } \\
\text { (Xylanaz) genleri }\end{array}$ \\
\hline Kolza & $\begin{array}{l}\text { Yağ asidi zincir azaltma ve } \\
\text { laurin asit artış1 }\end{array}$ & Asetil-ACP-Tioesteraz spesifik geninin transferi \\
\hline $\begin{array}{l}\text { A. thaliana, } \\
\text { Kolza }\end{array}$ & PHB ve $\mathrm{PHB} / \mathrm{V}$ üretimi & $\begin{array}{l}\text { R. eutropha'dan 3-Ketotiyolaz, Asetoasetil-Coa Reduktaz, PHA- } \\
\text { Syntaz enzimleri } \\
\text { ilvA466, BktB, phbB, phbC genlerinin transferi }\end{array}$ \\
\hline Çeltik & B karoten & $\begin{array}{lcccc}\text { Narcissuus türleri veya } & E . & \text { uredovora'dan } & \text { Terpenoid } \\
\text { metabolizmasının anahtar enzimleri }\end{array}$ \\
\hline Çeltik & Demir içeriği & $\begin{array}{l}\text { Phaseolus vulgaris'ten bir demir geni, A. fumigatus'tan bir Phytase } \\
\text { geni }\end{array}$ \\
\hline Patates & Nişasta içeriği & AGPaz geninin E. coli'den transferi \\
\hline Domates & Lycopin ve Lutein oran 1 & Phytoenin, lycopine değişimi için gen transferi \\
\hline
\end{tabular}

\section{Hoffmann, 1997.}

GDO'lu ürünlerin onaylanması için yüksek maliyet gerektirmesi ve sıkı düzenlemeler, ürünlerin marketleme sürecini geciktirebilir (Falck-Zepeda et all. 2012). Dolayıs1 ile son zamanlarda biyoteknolojik yaklaşımlardan biri olan CRSPR/Cas teknolojisinin bazı uygulamaları GDO düzenlemeleri kapsamına girmemektedir (Kim and Kim, 2016). 2017'de FDA CRISPR ile genetiği modifiye edilmiş olan yağ içeriği arttırılmış ketencik bitkisi (Camelina sativa) ve kurak-tolerant soya (Gylicine max) bitkisinin pazarlanmasına onay vermiş ve CRISPR/Cas ile düzenlenmiş bitkilerin GDO'lu bitkiler katagorisine tabi tutulmadığı gösterilmiştir (Waltz, 2018).

CRISPR sistemi bakteri ve arkealarde mevcut olan bakteriyofaj, eksojen plazmid gibi yabancı genomlara karşı savunmada görevli adaptiv immün mekanızmasıdır (Sternberg et all., 2016). Genom mühendisliği aracılığıyla oluşturulan Cas9'un genom düzenlemenin bir aracı olarak kullanılabileceğinin keşfi ile 2013'den sonra CRISPR/cas teknolojisi ile genom düzenleme çalışmaları hız kazanmıştır. Günümüze kadar bu teknoloji biyomedikal, biyoteknoloji, gen terapisi, biyo-yakıt endüstrisi gibi alanlarda uygulanmış ve ayrıca tarım alanında önemli olan sorgum, pirinç, buğday ve misır gibi bitkilerin genomlarının düzenlemesinde kullanılmıştır (Demirel et al., 2020). Model bitki türü olan Arabidopsis thaliana'da CRISPR/Cas ile ilişkili birçok çalışma mevcut olmasına rağmen, soya (Cai et al., 2015; Li et al., 2015), Brassica ssp (Yang et al., 2017), pamuk (Zhang et al., 2018) ve ketencik (Jiang et al., 2017) gibi yağ bitkisi türlerinde genom düzenleme çalışmaları sınırlı olmakla birlikte son zamanlarda araştırma sayısı artmaktadır.

Tohum boyutu ve sayısı birim alandan elde edilen yağ bitkisinin verimini belirleyen önemli bir kriterdir. Bitki yapısı ve büyüme özelliklerinin değiştirilmesi bitkinin adaptasyonunu ve tohum verimini önemli ölçüde arttırabilir (Teicmann and Muhr, 2015). Özellikle CLAVATA (CLV1, CLV2 ve CLV3) gibi gen grupları bitki boyunun belirlenmesinde önemli rol oynamaktadır.
$\mathrm{Bu}$ üç $\mathrm{CLV}$ geninin herhangi birinde fonksiyonu etkileyen mutasyonlar meristematik hücrelerin aşırı büyümesine neden olarak organ oluşumunda bir gecikmeye yol açmaktadır (Clark et al., 1993; Clark et al., 1995; Schoof et al., 2000). Tarımsal performans bakımından bu etki, çiçek sayısının artması ve meyve morfolojisinde değişim gibi arzu edilebilir özelliklere katk1 sağlayabilir. CLV1 ve CLV3 mutasyonlarının Brassica juncea ve Brassica rapa bitkilerinde tohum verimini arttırdığ bildirilmiş̧tir (Yadava et al., 2014; Xu et al., 2017). Kendiliğinden ya da uyarılmış mutasyon türevli çok lokuslar ve mutantlar Brassica napus'ta henüz tanımlanmamıştır. Yang et al. (2018), NHEJ aracılı genom düzenleme mekanizmasını kullanarak B. napus bitkisinde CLV1, CLV2 ve CLV3 genlerinde mutasyon oluşturmuşlardır. Mutant bitkilerin yabani tip kontrol ile karşılaştırıldığında daha fazla tohum sayısına, tohum ağırlığına ve yaprak sayısına sahip olduğu gösterilmiştir (Yang et al., 2018).

Kökteki dallanmanın artması birçok bitkide tohum veriminin artmasına katkı sağlayabilir. Strigolakton biyosentezinde yer alan bir sitokrom P450 monooksijenazı (CYP711A1) kodlayan MORE AXILLARY GROWTH 1 (MAX1) geni, çoğu bitki türünde vejetatif aksiller tomurcuk büyümesinin bir baskılayıcısı olarak rol oynamaktadır (Lazar ve Goodman, 2006 ; Zhang, Cheng, vd., 2018; Zheng vd., 2020). Eş zamanlı olarak dört B. napus BnaMAX1 allelin CRISPR / Cas9 ile NHEJ aracıllğıyla susturulmasıyla, hem dal hem de tohum veriminde önemli artışa neden olan yarı cüce fenotipli bitkiler elde edilmiştir (Zheng et al. al., 2020).

SQUAMOSA PROMOTER BAĞLAYICI PROTEINLIKE (SPL) transkripsiyon faktörlerinin, vejetatif-üreme geçişleri ve filiz dallanmasını içeren birçok bitki gelişim sürecinde hayati bir rol oynadığı bilinmektedir (Wang ve Wang, 2015). Bu genlerin bir alt kümesinin (AP1 / SQUA homologları dahil) karmaşık bir çiçeklenme düzenleyici ağda merkezi işlevlere sahiptir (Wang, 
Çek, vd. 2009; Wang ve Wang, 2015). Sürgün dallanmasındaki farklı SPL genlerinin rolü nedeniyle, bu genlerdeki mutasyonlar bitkisel biyokütlede artışlara neden olabilmektedir (Schwarz ve diğerleri, 2008; Gou ve diğerleri, 2018), bu da dolaylı yoldan tohum sayısında artışa yol açabilir. Bao et al. (2019), CRISPR/cas9 ile soyada farklı SPL9 homologlarının susturulması ile bitkilerde daha yüksek yaprak, nod ve dal sayısı gözlediklerini ve elde edilen fenotipik özelliklerin bitkide tohum sayısını arttırmada etkili olabileceğini ifade etmişlerdir. Bir yağ bitkisi olan soyada CRISPR/Cas9 aracılığıyla bir başka genom düzenleme Cai et al. $(2018,2020)$ tarafından gerçekleştirilmiştir. Araştırmacilar hedef gen olarak FLOWERING LOCUS T (FT)'yi belirlemişlerdir. Bu gen çiçeklenme sürecinde merkezi rol oynayan yüksek derecede korunmuş özelliğe sahiptir. Soyada iki FT homoloğunun (GmFT2a ve GmFT5a) NHEJ mekanizması ile oluşturulan GmF2a/GmFT5a bakımından çift mutant bitkilerin kontrol bitkiler ile karşılaştırıldığında her bitki başına tohum sayısında nispeten $\% 250$ artış gözlendiği rapor edilmiştir (Cai et al., 2020). Yağ bitkilerinde tohum boyutu, tohum verimliliği ve tohum sayısının arttırılması amacıyla CRISPR/Cas genom düzenleme çalışmaları diğer alanlardaki genom düzenleme çalışmalarına kıyasla az sayıdadır. Bu tarz çalışmaların yanı sıra CRIPR/Cas yaklaşımı ile yağ kompozisyonunun düzenlenmesi üzerine çalışmalar başlangıç seviyesindedir.

Keten (flax) ve ketencik (camelina) gibi bitkilerden elde edilen yağlarda yüksek seviyede PUFA (polyunsaturated fatty acids/çoklu doymamış yağ asitleri)'nın sağlık yönünden birçok faydası varken, daha yüksek MUFA (monounsaturated fatty acids/Tekli doymamış yağ asitleri) içeren yağlara göre oksidasyona daha duyarlıdırlar (Belide et al., 2012). Dolayısıyla MUFA oranı yüksek PUFA oranı düşük bitkisel yağlar çoğu besin uygulamaları için arzu edilebilir form olmuştur. Kolza, ayçiçeği, zeytin, soya, ketencik ve keten gibi çeşitli yağ bitkisi türlerinde geleneksel 1slah ve transgenik yaklaşımlar kullanılarak 18:1 oranında MUFA/PUFA içeren tohum yağları elde edilmiştir (Singer et al., 2014; Velasco and Fernández-Martínez, 2002; Chen et al., 2015). FAD2 (fatty acid desaturase 2) genlerinde genom düzenleme araçları ile mutansyon oluşturularak 18:1 MUFA/PUFA oranına sahip tohum yağları piyasada yer almaktadir. CRISPR/cas9 ve TALEN ile FAD2 genlerinin düzenlenmesi soya (Al Amin et al., 2019; Demorest et al., 2016; Do et al., 2019; Haun et al., 2014) ve ketencik bitkisinde gerçekleştirilmiştir (Jiang et al., 2017). Genomu düzenlenen bu bitkilerde kontrol ile karşılaştırıldığında 18:1 MUFA/PUFA oranının tohumlarda $\% 50$ ile $\% 83$ arasında arttığı gösterilmiştir. Bunun yanı sıra araştırmacılar tohumlarda bulunan doymamış uzun yağ asit içeriğini düşürmek ve kısa yă asit içeriğini arttırmak adına genom düzenleme tekniklerini kullanmıștır (Ozseyhan et al., 2018, McGinn et al., 2019). İnsan sağlığı için yüksek MUFA içeriğine sahip yağlar arzu edilse de endüstriyel uygulamalar için yüksek SFA (saturated fatty acids/doymuş yağ asitleri) içeren bitki yağları tercih edilmektedir. Lyzenga et al. ( 2019), CRISPR/Cas aracılığıyla tohum depo proteinini kodlayan CRUC (cruciferin C) lokusunda modifikasyon ile ketencik bitkisinde toplam SFA'nın arttığını rapor etmişlerdir.

\section{Sonuç}

Tarımsal faaliyetlerde beslenme amacıyla her türlü canlı organizmadan yararlanılmaktadır. Biyoteknolojik çalışmalar ile canlı organizmalardan daha fazla yararlanmak için teknolojik yöntemler artmaktadır. Genetik mühendisliği araçların gelişmesi bir organizmadan başka bir organizmaya uygun karakterlerin kazandırılması mümkün hale gelmiştir. Genetik modifikasyonlarla bitki verim ve kalitesinin arttırılması, hastalık ve zararlılara karşı direnç, biyotik ve abiyotik stres faktörlerine dayanıklı ve besin içeriklerinin değiştirilmesi gibi çeşitli çalışmalar yapılmaktadır.

Genetik modifikasyonlarla bitki besin içeriklerinde kimyasal değişim ile fizyolojik uygunlukla birlikte, yararlı veya istenmeyen bileşenlerin ise miktarının arttırılması ya da azaltılması mümkün hale gelmiştir. Son yıllarda kolza, keten ve haşhaş benzeri bitkilerde yapılan yağ asidi kompozisyonundaki değişim çalışmaları örnek teşkil etmektedir. Yağ asidi kompozisyonu üzerine CRISPR/cas ile kolza, ayçiçeği, zeytin, ketencik gibi çeşitli bitkilerde MUFA/PUFA içeren yağlar elde edilmiştir. Ayrıca doğmamış yağ asidi içeriğini düşürmek/arttırmak işlemlerini sağlayan genom düzenleme yöntemleri geliştirmişlerdir.

Yapılan tüm gen modifikasyon yöntemleri gıda ve ekonomisi açıdan büyük önem arz etmektedir. Özellikle artan dünya nüfusunun beslenme ihtiyaçlarının karşılanması açısından yapılan bu çalışmalar umut kaynağı olmaktadır. Ancak biyoteknolojik yöntemlerin artılarının yanında olası risklerinin de göz önünde bulundurulması gerekmektedir. Bu nedenle bu kazanımların agronomik çalışmalarıyla beraber insan-çevre interaksiyonları ve insan sağlığına etkileri ve kabul edilebilirliği için gerekli araştırmaların sayısının arttırılması gerekmektedir.

\section{Kaynakça}

Al Amin, N., Ahmad, N., Wu, N., Pu, X., Ma, T., Du, Y., ... \& Wang, P. (2019). CRISPR-Cas9 mediated targeted disruption of FAD2-2 microsomal omega-6 desaturase in soybean (Glycine max. L). BMC biotechnology, 19(1), 1-10. https://doi.org/10.1186/s12896-019-0501-2

Awais, M., Pervez, A., Yaqub, A., Sarwar, R., Alam, F., \& Siraj, S. (2010). Current status of biotechnology in health. American Eurasian J. Agric. \& Environ. Sci, 7(2), 210-220.

Bao, A., Chen, H., Chen, L., Chen, S., Hao, Q., Guo, W., ... \& Zhang, C. (2019). CRISPR/Cas9-mediated targeted mutagenesis of GmSPL9 genes alters plant architecture in soybean. BMC plant biology, 19(1), 1-12. https://doi.org/10.1186/s12870-019-1746-6

Belide, S., Petrie, J. R., Shrestha, P., \& Singh, S. P. (2012). Modification of seed oil composition in Arabidopsis by artificial microRNA-mediated gene silencing. Frontiers in plant science, $3, \quad 168$. https://doi.org/10.3389/fpls.2012.00168

Cai, Y., Chen, L., Liu, X., Guo, C., Sun, S., Wu, C., ... \& Hou, W. (2018). CRISPR/Cas9-mediated targeted mutagenesis of GmFT2a delays flowering time in soya bean. Plant biotechnology journal, 16(1), 176-185. https://doi.org/10.1111/pbi.12758

Cai, Y., Chen, L., Liu, X., Sun, S., Wu, C., Jiang, B., ... \& Hou, W. (2015). CRISPR/Cas9-mediated genome editing in soybean hairy roots. PLoS One, 10(8), e0136064. https://doi.org/10.1371/journal.pone.0136064

Cai, Y., Wang, L., Chen, L., Wu, T., Liu, L., Sun, S., ... \& Han, T. (2020). Mutagenesis of GmFT2a and GmFT5a mediated by CRISPR/Cas9 contributes for expanding the regional adaptability of soybean. Plant biotechnology journal, 18(1), 298-309. https://doi.org/10.1111/pbi.13199 
Chen, Y., Zhou, X. R., Zhang, Z. J., Dribnenki, P., Singh, S., \& Green, A. (2015) Development of high oleic oil crop platform in flax through RNAi-mediated multiple FAD2 gene silencing. Plant Cell Reports, 34:643-653. https://doi.org/10.1007/s00299-015-1737-5

Clark, S. E., Running, M. P., \& Meyerowitz, E. M. (1993). CLAVATA1, a regulator of meristem and flower development in Arabidopsis. Development, 119(2), 397-418.

Clark, S. E., Running, M. P., \& Meyerowitz, E. M. (1995). CLAVATA3 is a specific regulator of shoot and floral meristem development affecting the same processes as CLAVATA1. Development. 121: 2057-2067.

Demirel, F. 2020. Bitki ve Hayvan Biyoteknolojisi; Hücresel Tarım ve Nano-Teknoloji. Journal of Agriculture, 3(2), 1-9. https://doi.org/10.46876/ja.822503

Demirel, S., Usta, M,., \& Demirel, F. (2020). Fitopatojenlere Karşı Dayanıklılıkta CRISPR/Cas Teknolojisi. Avrupa Bilim ve Teknoloji Dergisi, (20), 693-702. https://doi.org/10.31590/ejosat.765369

Demorest, Z. L., Coffman, A., Baltes, N. J., Stoddard, T. J., Clasen, B. M., Luo, S., ... \& Mathis, L. (2016). Direct stacking of sequence-specific nuclease-induced mutations to produce high oleic and low linolenic soybean oil. BMC plant biology, 16(1), 225. https://doi.org/10.1186/s12870016-0906-1

Do, P. T., Nguyen, C. X., Bui, H. T., Tran, L. T., Stacey, G., Gillman, J. D., ... \& Stacey, M. G. (2019). Demonstration of highly efficient dual gRNA CRISPR/Cas9 editing of the homeologous GmFAD2-1A and GmFAD2-1B genes to yield a high oleic, low linoleic and $\alpha$-linolenic acid phenotype in soybean. BMC plant biology, 19(1), 311. https://doi.org/10.1186/s12870-019-1906-8

Falck-Zepeda, J., Yorobe Jr, J., Husin, B. A., Manalo, A., Lokollo, E., Ramon, G., ... \& Sutrisno. (2012). Estimates and implications of the costs of compliance with biosafety regulations in developing countries. GM crops \& food, 3(1), 52-59. https://doi.org/10.1080/21645698.2019.1612689

Ghafoor, K., Özcan, M. M., Fahad, A. J., Babiker, E. E., \& Fadimu, G. J. (2019). Changes in quality, bioactive compounds, fatty acids, tocopherols, and phenolic composition in oven-and microwave-roasted poppy seeds and oil. LWT, 99, 490-496. https://doi.org/10.1016/j.lwt.2018.10.017

Gou, J., Debnath, S., Sun, L., Flanagan, A., Tang, Y., Jiang, Q., ... \& Wang, Z. Y. (2018). From model to crop: functional characterization of SPL 8 in $M$. truncatula led to genetic improvement of biomass yield and abiotic stress tolerance in alfalfa. Plant biotechnology journal, 16(4), 951-962. https://doi.org/10.1111/pbi.12841

Haun, W., Coffman, A., Clasen, B. M., Demorest, Z. L., Lowy, A., Ray, E., ... \& Mathis, L. (2014). Improved soybean oil quality by targeted mutagenesis of the fatty acid desaturase 2 gene family. Plant biotechnology journal, 12(7), 934-940. https://doi.org/10.1111/pbi.12201

Hoffmann, T. (1997). Gentransfer bei höheren Pflanzen. Biologische Grundlagen der Pflanzenzüchtung. Parey Bucherverlag, Berlin, 275-323. https://doi.org/10.29133/yyutbd.468218

Jiang, W. Z., Henry, I. M., Lynagh, P. G., Comai, L., Cahoon, E. B., \& Weeks, D. P. (2017). Significant enhancement of fatty acid composition in seeds of the allohexaploid, Camelina sativa, using CRISPR/Cas9 gene editing. Plant biotechnology journal, 15(5),

$648-657$

https://doi.org/10.1111/pbi.12663

Jiang, W. Z., Henry, I. M., Lynagh, P. G., Comai, L., Cahoon, E. B., \& Weeks, D. P. (2017). Significant enhancement of fatty acid composition in seeds of the allohexaploid, Camelina sativa, using CRISPR/Cas9 gene editing. Plant biotechnology journal, 15(5), 648-657. https://doi.org/10.1111/pbi.12663

Kim, J., \& Kim, J. S. (2016). Bypassing GMO regulations with CRISPR gene editing. Nature biotechnology, 34(10), 10141015. https://doi.org/10.1038/nbt.3680

Lack, G. (2002). Clinical risk assessment of GM foods. Toxicology letters, 127(1-3), 337-340. https://doi.org/10.1016/S0378-4274(01)00517-3

Lazar, G., \& Goodman, H. M. (2006). MAX1, a regulator of the flavonoid pathway, controls vegetative axillary bud outgrowth in Arabidopsis. Proceedings of the National Academy of Sciences, 103(2), 472-476. https://doi.org/10.1073/pnas.0509463102

Li, Z., Liu, Z. B., Xing, A., Moon, B. P., Koellhoffer, J. P., Huang, L., ... \& Cigan, A. M. (2015). Cas9-guide RNA directed genome editing in soybean. Plant physiology, 169(2), 960-970. https://doi.org/10.1104/pp.15.00783

Lyzenga, W. J., Harrington, M., Bekkaoui, D., Wigness, M., Hegedus, D. D., \& Rozwadowski, K. L. (2019). CRISPR/Cas9 editing of three CRUCIFERIN C homoeologues alters the seed protein profile in Camelina sativa. BMC plant biology, 19(1), 292. https://doi.org/10.1186/s12870-019-1873-0

McGinn, M., Phippen, W. B., Chopra, R., Bansal, S., Jarvis, B. A., Phippen, M. E., ... \& Durrett, T. P. (2019). Molecular tools enabling pennycress (Thlaspi arvense) as a model plant and oilseed cash cover crop. Plant biotechnology journal, 17(4), 776-788. https://doi.org/10.1111/pbi.13014

Mucci, A., \& Hough, G. (2004). Perceptions of genetically modified foods by consumers in Argentina. Food Quality and Preference, 15(1), 43-51. https://doi.org/10.1016/S09503293(03)00021-1

Ohlrogge, J. B. (1994). Design of new plant products: engineering of fatty acid metabolism. Plant physiology, 104(3), 821. https://doi.org/10.1104/pp.104.3.821

Ozseyhan, M. E., Kang, J., Mu, X., \& Lu, C. (2018). Mutagenesis of the FAE1 genes significantly changes fatty acid composition in seeds of Camelina sativa. Plant Physiology and Biochemistry, 123, 1-7. https://doi.org/10.1016/j.plaphy.2017.11.021

Peter, K. V. (Ed.). (2012). Handbook of herbs and spices. Elsevier.

Schoof, H., Lenhard, M., Haecker, A., Mayer, K. F. X., Jurgens, G., \& Laux, T. (2000). The stem cell population $€$ of Arabidopsis shoot meristems in maintained by a regulatory loop between the CLAVATA and WUSCHEL genes. Cell. 100: 635-644. doi:10.1016/S0092- 8674(00)80700-X

Schwarz, S., Grande, A. V., Bujdoso, N., Saedler, H., \& Huijser, P. (2008). The microRNA regulated SBP-box genes SPL9 and SPL15 control shoot maturation in Arabidopsis. Plant molecular biology, 67(1-2),

183-195. https://doi.org/10.1007/s11103-008-9310-Z

Singer, S. D., Weselake, R. J., \& Rahman, H. (2014) Development and characterization of low $\alpha$-linolenic acid Brassica oleracea lines bearing a novel mutation in a 'class a' FATTY ACID DESATURASE 3 gene. BMC Genetics, 15:94. https://doi.org/10. 1186/s12863-014-0094-7. 
Sternberg, S. H., Richter, H., Charpentier, E., \& Qimron, U. (2016). Adaptation in CRISPR-Cas systems. Molecular cell, 61(6), 797-808. https://doi.org/10.1016/j.molcel.2016.01.030

Stirling, A., Glover, D., \& Millstone, E. (2015). Regulating Genetic Engineering: the limits and politics of knowledge.

Teichmann, T. \& Muhr, M. (2015). Shaping plant architecture. Front. Plant 233. https://doi.org/10.3389/fpls.2015.00233

Thierfelder, A., Lühs, W., \& Friedt, W. (1992). Breeding of industrial oil crops with the aid of biotechnology: a review. Industrial Crops and Products, 1(2-4), 261-271. https://doi.org/10.1016/0926-6690(92)90027-S

Turgut, K., Uranbey, S., \& Özcan, S. (2001). Antisens RNA Teknolojisi. Bitki Biyoteknolojisi: Genetik Mühendisliği ve Uygulamaları (Ed. S. Özcan, E. Gürel ve M. Babaoğlu). s, 401-420.

Uzogara, S. G. (2000). The impact of genetic modification of human foods in the 21 st century: A review. Biotechnology advances, 18(3), 179-206.

Velasco, L., \& Fernández-Martínez, J. M. (2002) Breeding oilseed crops for improved oil quality. Journal of Crop Production, 5: 309-344. https://doi.org/10.1300/J144v05n01_13

Waltz, E. (2018). With a free pass, CRISPR-edited plants reach market in record time. https://doi.org/10.1038/nbt0118-6b

Wang, H. \& Wang, H. (2015). The miR156/SPL module, a regulatory hub and versatile toolbox, gears up crops for enhanced agronomic traits. Mol. Plant. 8: 677-688. doi: 10.1016/j.molp.2015.01.008

Wenzel, G., \& Mohler, V. (2001). Innovationen in der Pflanzenbiotechnologie. Euro-Biotech, 2001, 108-111.
Yang, H., Wu, J. J., Tang, T., Liu, K. D., \& Dai, C. (2017). CRISPR/Cas9-mediated genome editing efficiently creates specific mutations at multiple loci using one sgRNA in Brassica napus. Scientific reports, 7(1), 1-13. https://doi.org/10.1038/s41598-017-07871-9

Yang, Y., Zhu, K., Li, H., Han, S., Meng, Q., Khan, S. U., ... \& Zhou, Y. (2018). Precise editing of CLAVATA genes in Brassica napus $L$. regulates multilocular silique development. Plant biotechnology journal, 16(7), 13221335. https://doi.org/10.1111/pbi.12872

Zhang, Y., Cheng, X., Wang, Y., Díez-Simón, C., Flokova, K., Bimbo, A., ... \& Ruyter-Spira, C. (2018). The tomato MAX1 homolog, SIMAX1, is involved in the biosynthesis of tomato strigolactones from carlactone. New Phytologist, 219(1), 297-309. https://doi.org/10.1111/nph.15131

Zhang, Z., Ge, X., Luo, X., Wang, P., Fan, Q., Hu, G., ... \& Wu, J. (2018). Simultaneous editing of two copies of Gh14-3-3d confers enhanced transgene-clean plant defense against Verticillium dahliae in allotetraploid upland cotton. Frontiers in plant science, $\quad 942$ https://doi.org/10.3389/fpls.2018.00842

Zheng, M., Zhang, L., Tang, M., Liu, J., Liu, H., Yang, H., ... \& Hua, W. (2020). Knockout of two Bna MAX 1 homologs by CRISPR/Cas9-targeted mutagenesis improves plant architecture and increases yield in rapeseed (Brassica napus L.). Plant biotechnology journal, 18(3), 644-654. https://doi.org/10.1111/pbi.13228 